\title{
Use of Virtual Reality as a Tool to Overcome the Post-Traumatic Stress Disorder of Pensioners
}

\author{
Ivan Kovar \\ Department of Mathematics, Tomas Bata University - Faculty of Applied Informatics, Nad Stranemi 4511, Zlin, 760 05, Czech Republic \\ E-mail:ikovar@utb.cz.
}

\begin{abstract}
The aim of this paper is to analyze the influence of virtual reality (VR) on overcoming post-traumatic stress disorder (PTSD) of pensioners suffering from anxiety disorders. PTSD is usually developed after some serious and traumatic event. This may be for example war conflict, flood, rape, fire, death, volcano eruptions, storms, car accidents, various explosions, torture, robberies or assaults. In the first part, the article deals with a theoretical description of VR itself, namely Samsung Gear VR device that was used for the VR therapy. In this part, there is also PTSD described. The main part is about the research itself, which analyzes not only the area of VR influence in overcoming PTSD but also the basic physiological body functions of respondents - the pensioners. The aim of the paper is to research whether it is possible to improve the health status of the monitored seniors through the purposeful help of VR. The results of our psychological tests after the application of the 6 months long research intervention at the time intervals are promising because there are provable decreases in depression stress. Treatment of PTSD is often difficult, take a lot of time and it is performed mostly with anxiolytics or hypnotic sleep medications. This research presents a method that could speed up therapy and also reduce the use of pharmaceuticals which is very important. Discussion and evaluation of the research are included.
\end{abstract}

Keywords — virtual reality; anxiety disorder; post-traumatic stress disorder; modern technologies; emotions.

\section{INTRODUCTION}

The paper deals with a topic of the use of VR as a tool to overcome the PTSD of citizens suffering from anxiety disorders in retirement age. Conclusions from different studies show us that treatment of PTSD is not optimal and very often the use of mood stabilizers, antipsychotics or anxiolytics (anxiety medications) is the core option how to deal with this disease [1], [2]. The use of modern technologies enables moving the spot of care from the traditional provider's office to mobile, online, and virtual environments which are less threatening for patients with PTSD, helping to overcome the core nature of the illness which includes avoidance and increased personal isolation [3]. The aim of this paper is to research whether it is possible to improve the health status of the monitored seniors through the purposeful help of VR. It would be ideal if the use of medication could be reduced. The research was conducted for 6 months (August 2018 to January 2019) on a small sample of respondents.

\section{MATERIAL AND METHOD}

VR can be explained as an electronic system that produces an artificially generated 3D made-up environment [4].
It was used the VR device Samsung Gear VR version SM-R325 together with Samsung Galaxy S7 Edge smartphone for our research. We used this combination of devices because it was optimal for our needs. It is easy to transport, possible to use in a seated position and with sufficient video resolution for our video content [5].

\section{A. Description of Samsung Gear VR}

Samsung Gear VR was developed by Samsung Electronics in collaboration with Oculus. In the easiest way, the Samsung Gear VR can be described as a head-mounted system for a compatible smartphone to give us VR experience. We decided to use Samsung Galaxy S7 Edge smartphone. The smartphone located in the VR unit is used to create all the VR experiences. In VR environment, it is possible to interact with the use of a touchpad on the side of the unit or with the use of bluetooth controller. Any compatible smartphone works as the headset display and processor. It is connected to the smartphone via micro-USB. It delivers three degrees of freedom tracking with the use of an accelerometer, magnetometer and gyroscope. It means, it is possible to track the movement of the remote control and to track the rotation of your head. It is not possible to track the movement of the full body. The Samsung Gear VR also includes proximity sensor to detect when the device is on. It 
is designed to turn off the display and audio when there is no proximity sensor reading - when the headset is not being worn. The device itself weighs $345 \mathrm{~g}$ and together with the smartphone, it is $502 \mathrm{~g}$. The view field of the device is $101^{\circ}$ [6], [7].

In Fig. 1 can be seen Samsung Gear VR device that was used to create VR environment in our research.

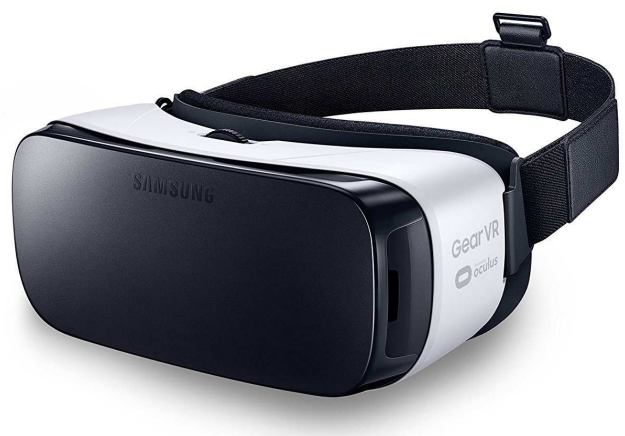

Fig. 1 VR device - Samsung Gear VR

\section{B. Post-traumatic Stress Disorder}

PTSD is a prolonged or delayed response of an individual to life-threatening situations. This disease often has a chronic progression and negatively affects the quality of life of patients [1].

PTSD can be characterized as "affective, cognitive, somatic and behavioural effects of psychological trauma". It is a chronic disorder for which a big amount of psychotherapies, drugs and new treatment programs are available [8], [9].

PTSD is usually developed after some serious and traumatic event. This may be for example wars, house fire, earthquakes, car accidents, death of a family relative, robberies or murders.

PTSD occurs in about one third of people who have been part of any such event. For PTSD, the rest period is relatively long. It may take up to six months to show signs of PTSD. PTSD symptoms may start within one month of a traumatic event, but sometimes symptoms may not appear until years after the event. These symptoms can cause significant problems in relationships or in social and work situations. There are most often three main symptom sets related to the re-experiencing of a traumatic event, the avoidance of internal and external impulses associated with the traumatic event and an increase of arousal including insomnia, bad dreams, irritability and impaired quality of concentration eventually isolation. [2], [10].

The lifetime prevalence of PTSD is 10,4-12,3\% for women and 5,0-6,0\% for men in the western population [11].

There can be involuntary cognitions after a traumatic experience. It means automatically appearing images, recalls or ideas. Victims of trauma very often go through involuntary memories and also involuntary nonmemories (knowledge about the situation that did not really happen). This knowledge can help to keep PTSD symptomology by contributing to an ongoing feeling of the present menace. It is unclear if people who were exposed to a past traumatic event with PTSD are more susceptible to nonmemories than people who are healthy without PTSD but who were also exposed to a past traumatic event [12].

Treatment of PTSD is often performed with anxiolytics; mainly with benzodiazepines, SSRI antidepressants or hypnotic sleep medications. Furthermore, psychotherapy such as interview, hypnosis or abreaction is appropriate. However, the ideal condition is when spontaneous remission occurs - it is healing without expert intervention. It always depends how emotionally stable the person is, and also on the stability of his/her personality. The support of the people around him/her is also very important [1].

\section{RESULTS AND DISCUSSION}

In the research part, we focused on four people (61-77 years old) who suffer from PTSD due to a previous traumatic event. The aim of the research was to find out whether it is possible with the appropriate and targeted VR action to help and improve health and the mental state of respondents.

\section{A. Introduction of the Research}

At the beginning of the research, we met individually with all the respondents in order to have a more detailed interview for understanding and detailed knowledge of their personal situation. The gained data can be found in Table 1 .

TABLE I

Personal Data of The Respondents

\begin{tabular}{|l|l|l|l|l|}
\hline & Respondent 1 & Respondent 2 & Respondent 3 & Respondent 4 \\
\hline Gender & man & man & woman & woman \\
\hline Age & 61 & 74 & 77 & 65 \\
\hline Medication & no & yes & no & yes \\
\hline Level of education & university & primary school & university & secondary school \\
\hline Trauma & direct & direct & direct & indirect \\
\hline $\begin{array}{l}\text { Traumatic event } \\
\text { flight accident }\end{array}$ & $\begin{array}{l}\text { cycling } \\
\text { accident }\end{array}$ & car accident accident, \\
daughter's death \\
\hline $\begin{array}{l}\text { Approximate year in which they first } \\
\text { experienced PTSD }\end{array}$ & 2013 & 2012 & 1995 & 2003 \\
\hline
\end{tabular}


Based on the interviews, unique $360^{\circ}$ video material for VR was prepared individually for each respondent. Their effect on the mental state of the respondents was monitored and the results were investigated with the use of four types of psychological tests.

\section{B. Background of the Research}

All observed respondents were exposed to VR effect for 6 months (August 2018 to January 2019). There were 25 sessions in total with each respondent and everyone was exposed to VR effect for two hours on every session. There were the sessions regularly every week. At every session during the research, all the participants underwent the same process in which they completed various anxiety tests. Before starting each rehabilitation session, we always measured the resting pressure, pulse and temperature as can be seen in Fig. 2. Subsequently, the rehabilitation session itself was performed with using a VR therapy adapted to each respondent individually. The actual pulse was real-time measured during this therapy session. Every time when the therapeutic session finished, there was a fifteen minutes long relaxation phase to calm down, relax and get rid of the tension. Once per every three months, a psychologist and a general practitioner were visited by the respondent suffering from PTSD to consult respondent's psychological status, measured the basic physiological body functions, progress and other issues related to this research.

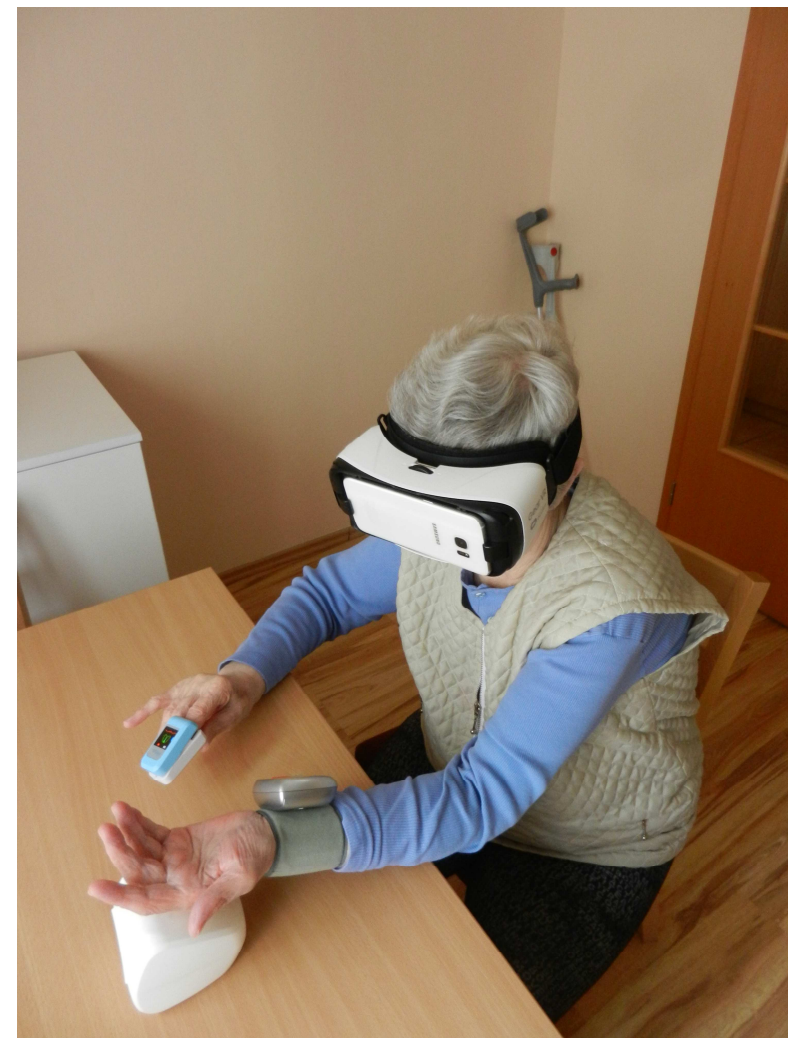

Fig. 2 Examined respondent during the measurement of the basic physiological body functions

\section{Individual Process of the Therapy}

In the Fig. 3 can be seen the respondent 2 during his VR therapy with a bicycle simulator together with a measuring the actual pulse at the load and visualizing the required VR environment. During this rehabilitation session, we have gradually simulated similar but easier traumatic event as he overcame in the past. A bicycle accident in which the respondent was hitted by a car caused a trauma that the respondent could not go through. Cycling used to be a favorite activity for the respondent, but he has mental problem with that in these days. The respondent has the bicycle simulator, but he does not enjoy indoor cycling in the room and he always gets anxiety when he starts to think about the outdoor cycling. At first, there was simulated VR cycling in the nature without any traffic. It was used to respondent gradually get used to VR. Subsequently, the density of road traffic, the number of cars, the sounds of the environment etc. were gradually increased. We were able to watch the reactions of the respondent during his therapies.

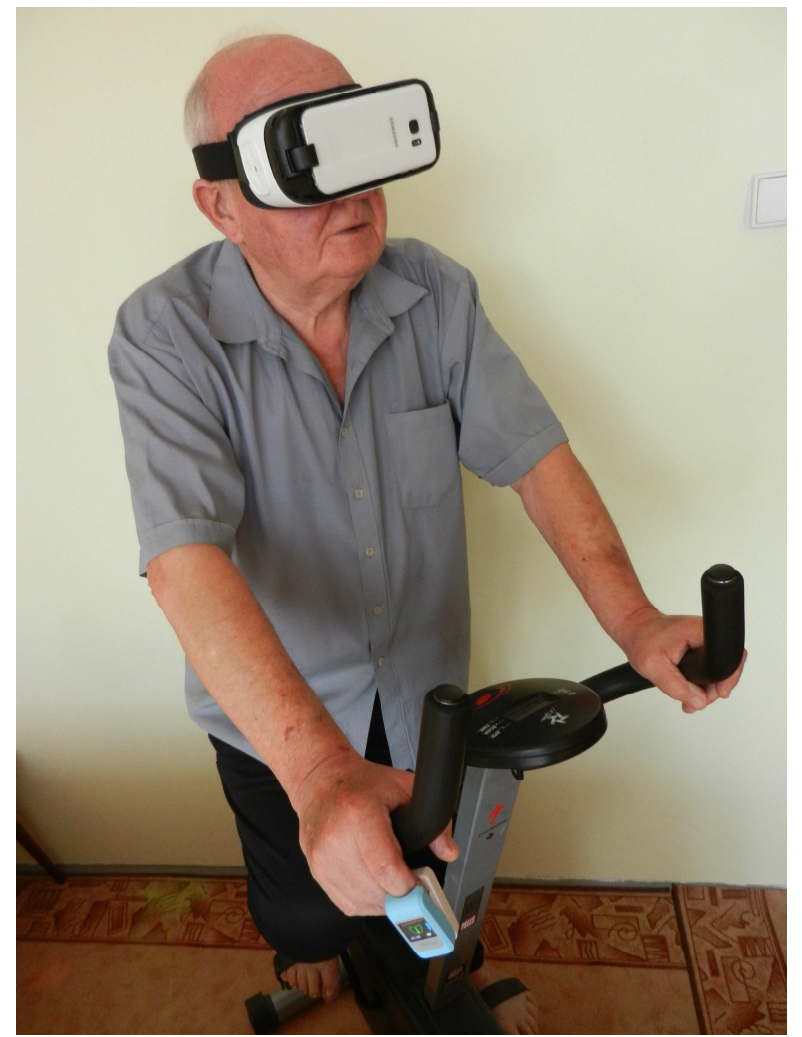

Fig. 3 The respondent during his VR therapy

The respondent 3 can be seen in Fig. 4 during her kinetic VR therapy. The respondent was participant in a car accident. During this traumatic event, she suffered from a leg injury. After healing of her leg injury, PTSD occurred. The respondent has significant sleeping problems and constantly returning the traumatic event. The respondent suffers from sickness fear of cars, has problem walking down the streets and squares - she has problems wherever where there can be cars. In the beginning, the respondent had a problem with the use of our VR device Samsung Gear VR. She did not know what to expect and because she is not a big fan of modern technologies, her expectations were low. The problem was that she has also the anxiety of using things which she is not familiar with. Therefore, in the beginning of the VR therapy, we had to give her extra time to get used to Samsung Gear VR device. 


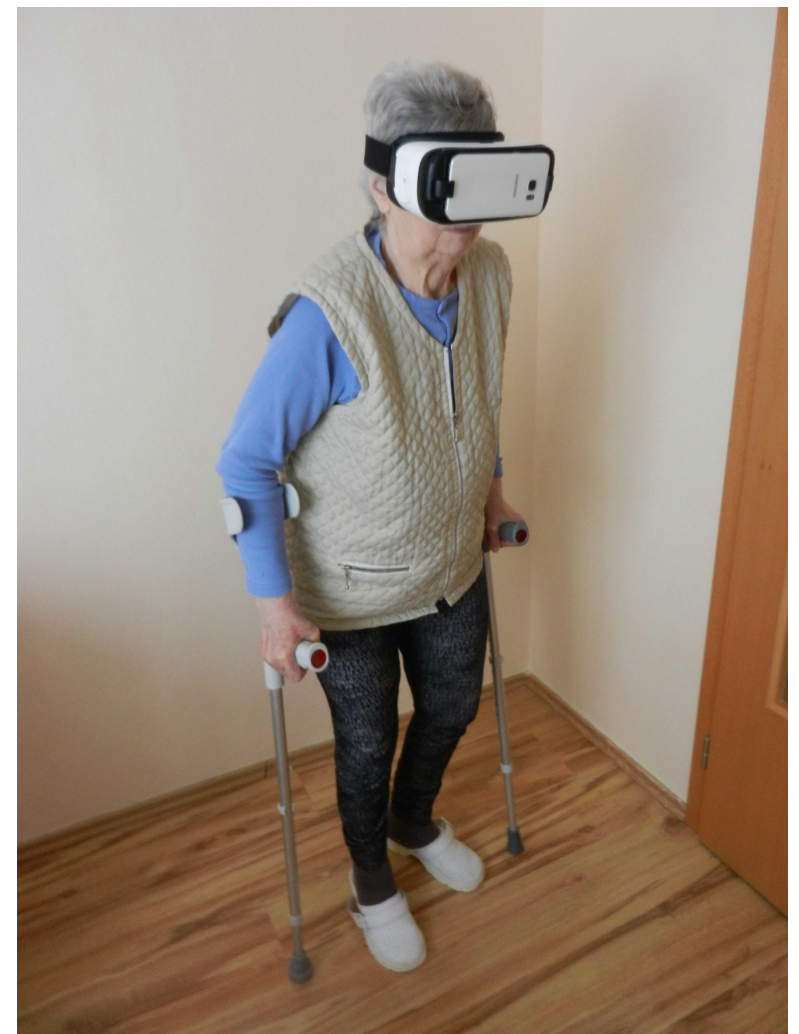

Fig. 4 The respondent during her VR therapy

VR therapy with the use of suitable gradually environment visualization has been used. At the beginning, a car has been visualized to the respondent where she was able to watch and move around the car. This situation was created to help the respondent with gradually overcoming the fear. Later, more cars were added to the scene. Gradually, cars began to move dynamically. In the later stages of the research, the respondent was placed virtually in the moving car. During the therapies we were able to observe and explore the respondent. Despite the fact that the patient had the problem with the use of VR therapy at the beginning, after $25 \mathrm{VR}$ sessions, there were seen and felt positive emotions and reactions.

\section{Anxiety Measurement Results}

The psychological status of respondents was investigated with the use of anxiety tests. We used well-known psychological tests, namely Brief Fear of Negative
Evaluation Scale (BFNE), Beck Anxiety Inventory (BAI), Trail Making Test (TMT) and PCL-5 Test.

1) Brief Fear of Negative Evaluation Scale (BFNE): This test analyzes anxiety connected with the perception of a negative rating. The test contains 12 questions describing fear or concern. The respondent indicates the level that best applies to them on a scale of 1 to 5, where 1 means: does not apply to me at all, and 5: extreme applies to me. Four from the twelve questions represent the absence of the scare or concern, the rest eight questions represent scare or concern. The scale for this test is from 12 to 60 . If a score is higher then there is a bigger level of anxiety [13].

The gained results of BFNE test from the individual measurement can be seen in Table 2 and in Fig. 5.

TABLE II

Results Of Bfne Measurement

\begin{tabular}{|l|l|l|l|l|}
\hline \multirow{2}{*}{$\begin{array}{l}\text { Session } \\
\text { Number }\end{array}$} & \multicolumn{4}{|c|}{ Value of BFNE } \\
\cline { 2 - 5 } & Resp. 1 & Resp. 2 & Resp. 3 & Resp. 4 \\
\hline 1 & 45 & 47 & 53 & 51 \\
\hline 2 & 45 & 48 & 53 & 52 \\
\hline 3 & 44 & 48 & 52 & 52 \\
\hline 4 & 45 & 46 & 53 & 51 \\
\hline 5 & 43 & 46 & 51 & 50 \\
\hline 6 & 42 & 44 & 50 & 47 \\
\hline 7 & 42 & 45 & 50 & 48 \\
\hline 8 & 42 & 43 & 51 & 45 \\
\hline 9 & 43 & 44 & 50 & 45 \\
\hline 10 & 41 & 44 & 49 & 45 \\
\hline 11 & 40 & 44 & 47 & 46 \\
\hline 12 & 40 & 43 & 46 & 44 \\
\hline 13 & 40 & 42 & 47 & 44 \\
\hline 14 & 37 & 42 & 45 & 42 \\
\hline 15 & 34 & 42 & 44 & 41 \\
\hline 16 & 34 & 43 & 40 & 41 \\
\hline 17 & 32 & 41 & 43 & 40 \\
\hline 18 & 33 & 41 & 43 & 40 \\
\hline 19 & 31 & 40 & 44 & 43 \\
\hline 20 & 30 & 40 & 43 & 40 \\
\hline 21 & 30 & 40 & 42 & 42 \\
\hline 22 & 29 & 39 & 42 & 40 \\
\hline 23 & 31 & 39 & 42 & 41 \\
\hline 24 & 30 & 40 & 43 & 40 \\
\hline 25 & 30 & 39 & 41 & 39 \\
\hline$\Delta \max$ & 15 & 8 & 12 & 12 \\
\hline & & & & \\
\hline
\end{tabular}

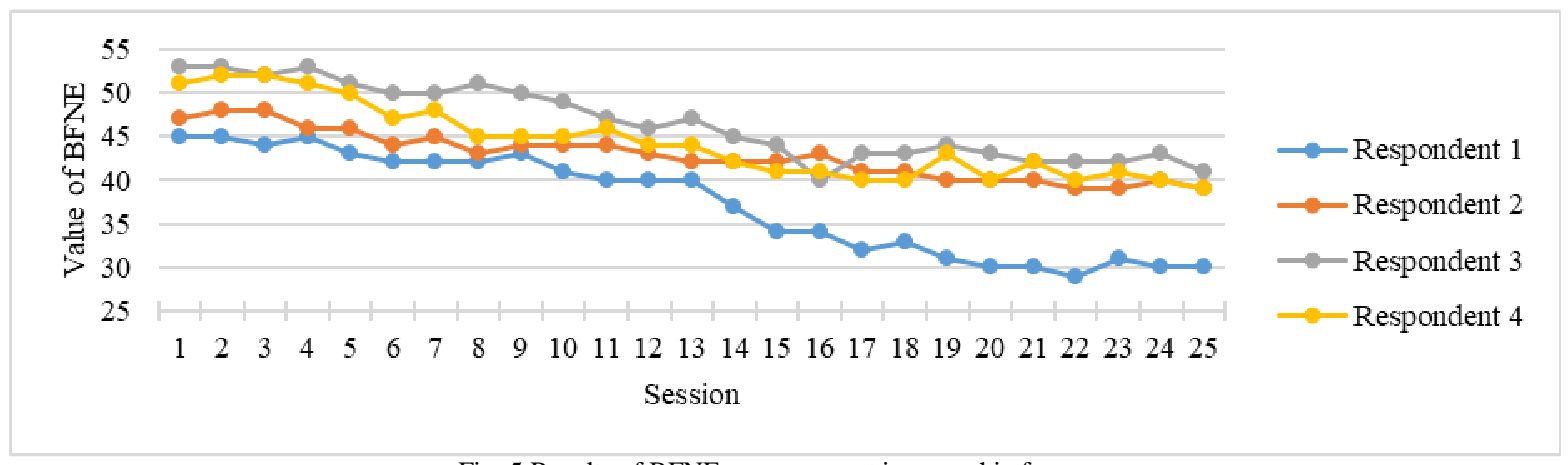

Fig. 5 Results of BFNE measurement in a graphic form 
2) Beck Anxiety Inventory (BAI): This method uses a list of 21 symptoms of anxiety, for example, afraid of losing control. People were asked to evaluate how affected they have been by each symptom during the last 7 days. There is a scale for each symptom (0 to 3). Where 0 means nothing / never and 3 means seriously / often. The final score can be on the scale of 0 to 63 . A higher score means there is a bigger level of anxiety. [14]

The gained results of BAI test can be seen in Table 3 and in Fig. 6.

TABLE III

RESULTS OF BAI MEASUREMENT

\begin{tabular}{|c|c|c|c|c|}
\hline \multirow{2}{*}{$\begin{array}{l}\text { Session } \\
\text { Number }\end{array}$} & \multicolumn{4}{|c|}{ Value of BAI } \\
\hline & Resp. 1 & Resp. 2 & Resp. 3 & Resp. 4 \\
\hline 1 & 43 & 45 & 52 & 54 \\
\hline 2 & 44 & 45 & 52 & 54 \\
\hline 3 & 43 & 43 & 51 & 52 \\
\hline 4 & 41 & 43 & 50 & 51 \\
\hline 5 & 40 & 43 & 50 & 51 \\
\hline 6 & 42 & 44 & 47 & 49 \\
\hline 7 & 40 & 43 & 47 & 47 \\
\hline 8 & 39 & 42 & 48 & 47 \\
\hline 9 & 39 & 42 & 46 & 46 \\
\hline 10 & 37 & 41 & 46 & 47 \\
\hline 11 & 35 & 41 & 47 & 46 \\
\hline 12 & 36 & 41 & 45 & 45 \\
\hline 13 & 35 & 41 & 45 & 43 \\
\hline 14 & 36 & 40 & 45 & 42 \\
\hline 15 & 35 & 41 & 44 & 42 \\
\hline 16 & 35 & 40 & 46 & 41 \\
\hline 17 & 34 & 39 & 44 & 44 \\
\hline 18 & 36 & 38 & 43 & 42 \\
\hline 19 & 35 & 38 & 45 & 42 \\
\hline 20 & 35 & 39 & 45 & 43 \\
\hline 21 & 35 & 37 & 44 & 41 \\
\hline 22 & 34 & 36 & 43 & 41 \\
\hline 23 & 33 & 34 & 44 & 41 \\
\hline 24 & 33 & 34 & 43 & 40 \\
\hline 25 & 34 & 33 & 42 & 37 \\
\hline$\Delta \max$ & 9 & 12 & 10 & 17 \\
\hline
\end{tabular}

3) Trail Making Test (TMT): This is one of the most popular neuropsychological tests. It helps us with visual searching, speed of reactions and the flexibility of mental health. There are 2 parts of TMT. In part A, the goal is to draw a line which connects step by step 25 encircled numbers located on a piece of paper. In part B, the goal is very similar. But respondent has to modulate numbers and letters located on a piece of paper. (1, A, 2, B, 3, C...) The final verdict is a time which is necessary to complete both tests. [15]

For the evaluation of TMT test (Part A), 29s is an average score and a score which is bigger than $78 \mathrm{~s}$ can be classified as an inadequate score. For the TMT test (Part B), the inadequate score is bigger than 273 s and an average score is classified 75s. [16]

The gained measurements of TMT (Part A) test can be seen in Table 4 and in Fig. 7 and the results of TMT (Part B) are in Table 5 and in Fig. 8.

TABLE IV

RESUlTS OF TMT (PART A) MEASUREMENT

\begin{tabular}{|l|l|l|l|l|}
\hline \multirow{2}{*}{$\begin{array}{l}\text { Session } \\
\text { Number }\end{array}$} & \multicolumn{4}{|c|}{ Value of TMT (Part A) } \\
\cline { 2 - 5 } & Resp. 1 & Resp. 2 & Resp. 3 & Resp. 4 \\
\hline 1 & 40 & 81 & 92 & 93 \\
\hline 2 & 37 & 80 & 90 & 95 \\
\hline 3 & 35 & 83 & 92 & 90 \\
\hline 4 & 36 & 81 & 86 & 94 \\
\hline 5 & 37 & 77 & 90 & 89 \\
\hline 6 & 35 & 79 & 88 & 89 \\
\hline 7 & 34 & 81 & 87 & 87 \\
\hline 8 & 36 & 80 & 88 & 86 \\
\hline 9 & 36 & 79 & 89 & 86 \\
\hline 10 & 35 & 78 & 90 & 88 \\
\hline 11 & 37 & 79 & 88 & 85 \\
\hline 12 & 35 & 82 & 86 & 85 \\
\hline 13 & 36 & 80 & 89 & 87 \\
\hline 14 & 35 & 78 & 85 & 85 \\
\hline 15 & 35 & 76 & 86 & 84 \\
\hline 16 & 34 & 77 & 85 & 85 \\
\hline 17 & 36 & 78 & 85 & 83 \\
\hline 18 & 34 & 76 & 84 & 80 \\
\hline 19 & 33 & 75 & 87 & 84 \\
\hline 20 & 35 & 74 & 85 & 85 \\
\hline 21 & 34 & 74 & 86 & 86 \\
\hline 22 & 33 & 76 & 85 & 80 \\
\hline 23 & 35 & 74 & 84 & 81 \\
\hline 24 & 34 & 74 & 83 & 80 \\
\hline 25 & 33 & 75 & 82 & 79 \\
\hline$\Delta \max$ & 7 & 6 & 10 & 14 \\
\hline & & & & \\
\hline
\end{tabular}

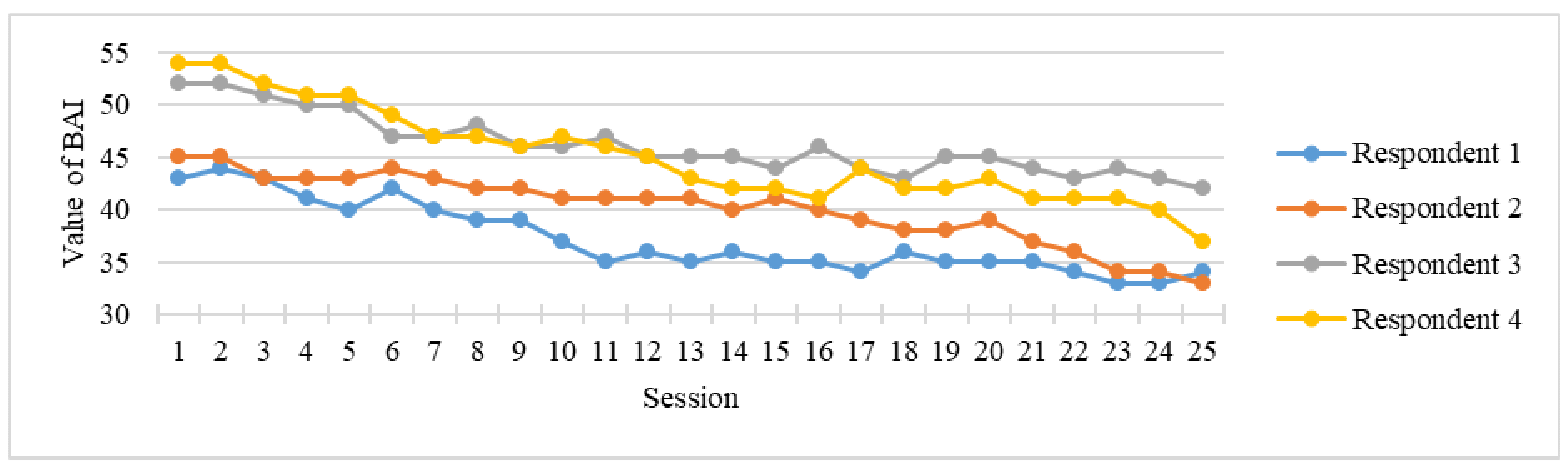

Fig. 6 Results of BAI measurement in a graphic form 


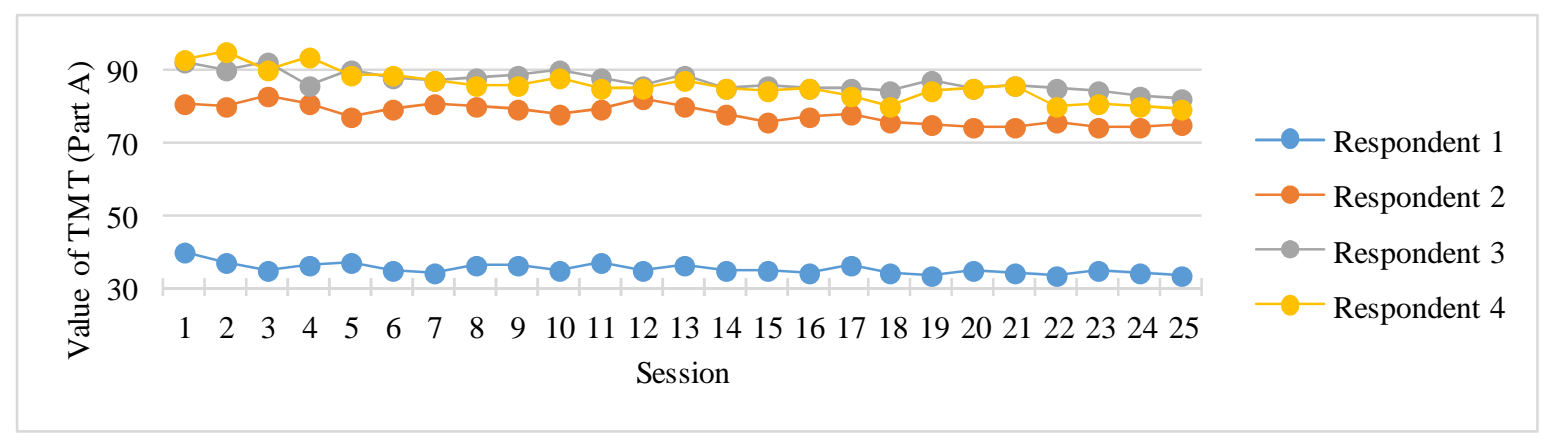

Fig. 7 Results of TMT (Part A) measurement in a graphic form

TABLE V

RESUlTS OF TMT (PART B) MEASUREMENT

\begin{tabular}{|c|c|c|c|c|}
\hline \multirow{2}{*}{$\begin{array}{l}\text { Session } \\
\text { Number }\end{array}$} & \multicolumn{4}{|c|}{ Value of TMT (Part B) } \\
\hline & Resp. 1 & Resp. 2 & Resp. 3 & Resp. 4 \\
\hline 1 & 95 & 277 & 290 & 305 \\
\hline 2 & 94 & 279 & 285 & 306 \\
\hline 3 & 93 & 270 & 294 & 302 \\
\hline 4 & 95 & 280 & 289 & 299 \\
\hline 5 & 91 & 265 & 287 & 301 \\
\hline 6 & 90 & 250 & 285 & 291 \\
\hline 7 & 93 & 275 & 291 & 299 \\
\hline 8 & 89 & 282 & 294 & 292 \\
\hline 9 & 89 & 261 & 280 & 285 \\
\hline 10 & 87 & 242 & 285 & 286 \\
\hline 11 & 89 & 260 & 283 & 289 \\
\hline 12 & 88 & 255 & 277 & 284 \\
\hline 13 & 89 & 249 & 282 & 285 \\
\hline 14 & 90 & 242 & 280 & 294 \\
\hline 15 & 88 & 256 & 275 & 288 \\
\hline 16 & 86 & 245 & 274 & 285 \\
\hline 17 & 86 & 244 & 278 & 281 \\
\hline 18 & 84 & 253 & 275 & 286 \\
\hline 19 & 86 & 240 & 276 & 280 \\
\hline 20 & 85 & 235 & 270 & 283 \\
\hline 21 & 88 & 242 & 276 & 280 \\
\hline 22 & 84 & 233 & 275 & 277 \\
\hline 23 & 85 & 236 & 272 & 280 \\
\hline 24 & 84 & 234 & 270 & 285 \\
\hline 25 & 84 & 233 & 267 & 281 \\
\hline$\Delta \max$ & 11 & 44 & 23 & 24 \\
\hline
\end{tabular}

4) PCL-5 Test: It is a 20-question test which is used to determine the presence and importance of PTSD symptoms. Questions on the PCL-5 coincide with the new DSM-5 psychiatric manual (released 2013) for PTSD. There are two typical examples of use PCL-5. Firstly, this test can be used as a helper in making a temporary diagnosis of PTSD. It can also be used to measure and follow symptoms over a longer period of time. This test has been approved as a means of checking symptom changes during the cure. This instrument generates a total score of 0 to 80 . If the gained score is 33 or bigger, it means that the respondent needs to take PTSD very seriously. It is desirable to be an active part of cognitive processing therapy or prolonged exposure. If the gained score is below 33, it means that the respondent is not classified as a patient sufferers PTSD. [17]

This test is often used more than one time to diagnose the change in PTSD symptoms over a longer period of time. If there is 5 points decrease, it means a faithful reduction in symptoms. It can be classified that change is not caused by a coincidence. If there is $10-20$ point reduction, we can say about a clinically important result. [18]

Fig. 9 represents obtained measurements in a graphical form. A slight change in curve shape occurred all the time and we can expect that with longer lasting VR therapy we would get even better results.

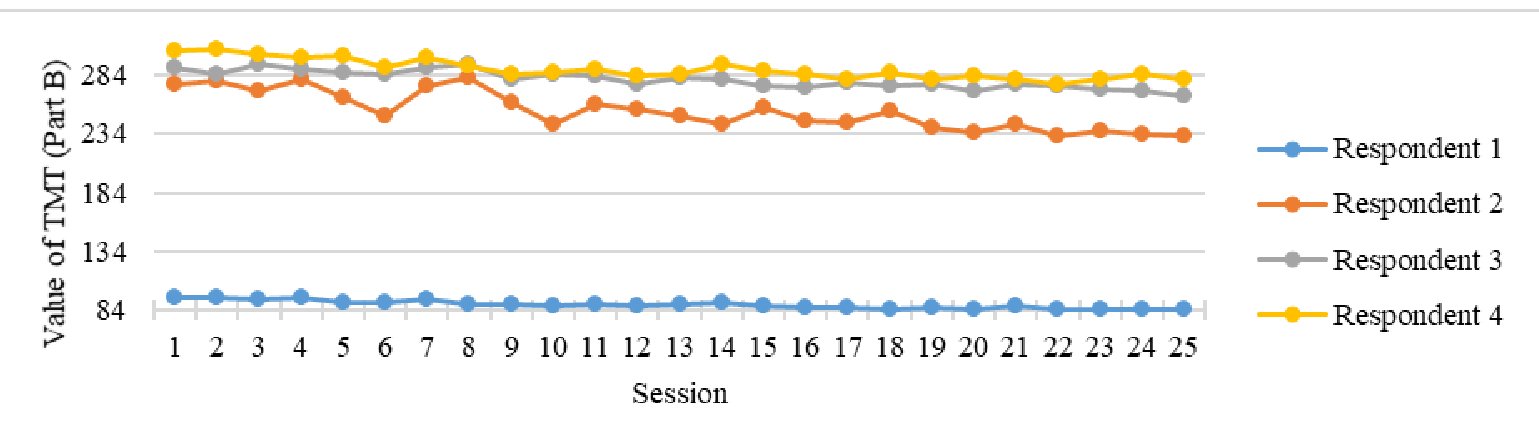

Fig. 8 Results Of TMT (Part B) Measurement In A Graphic Form 


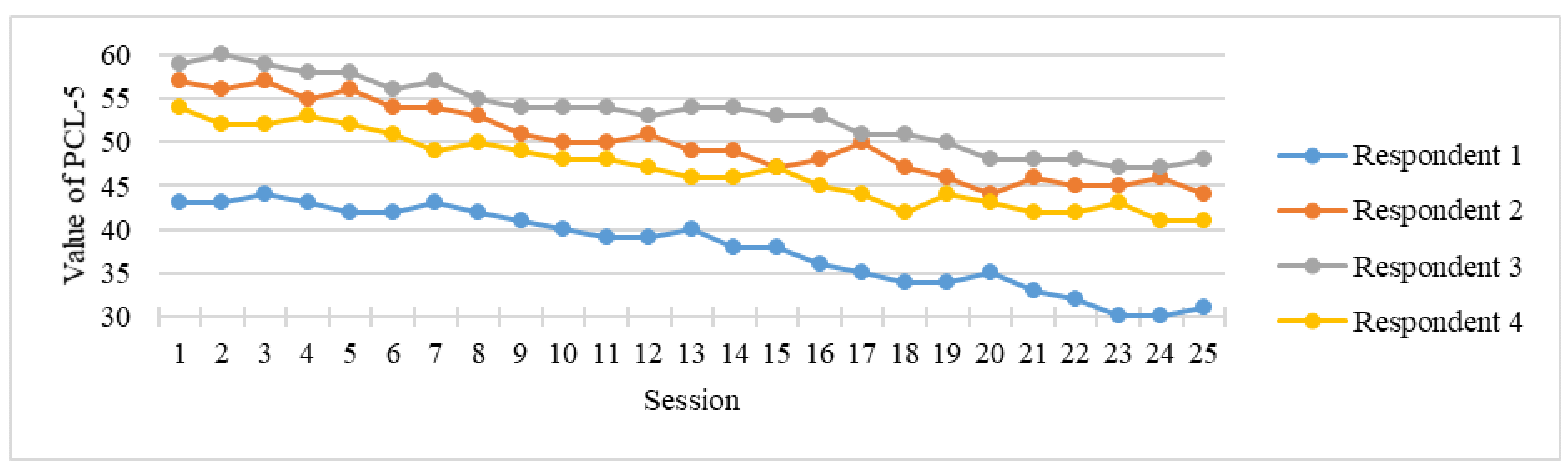

Fig. 9 Results of PCL-5 measurement in a graphic form

In Table 6 can be seen the results of PCL-5 measurement. From the gained results can be deduced that difference $\Delta \max$ between the first session and the last session is in every case more than 10 points (Respondent $1=12$, Respondent $2=13$, Respondent $3=11$, Respondent $4=13$ ). It means we can talk about the clinically significant change.

TABLE VI

RESULTS OF PCL-5 MEASUREMENT

\begin{tabular}{|l|l|l|l|l|}
\hline \multirow{2}{*}{$\begin{array}{l}\text { Session } \\
\text { Number }\end{array}$} & \multicolumn{4}{|c|}{ Value of PCL-5 } \\
\cline { 2 - 5 } & Resp. 1 & Resp. 2 & Resp. 3 & Resp. 4 \\
\hline 1 & 43 & 57 & 59 & 54 \\
\hline 2 & 43 & 56 & 60 & 52 \\
\hline 3 & 44 & 57 & 59 & 52 \\
\hline 4 & 43 & 55 & 58 & 53 \\
\hline 5 & 42 & 56 & 58 & 52 \\
\hline 6 & 42 & 54 & 56 & 51 \\
\hline 7 & 43 & 54 & 57 & 49 \\
\hline 8 & 42 & 53 & 55 & 50 \\
\hline 9 & 41 & 51 & 54 & 49 \\
\hline 10 & 40 & 50 & 54 & 48 \\
\hline 11 & 39 & 50 & 54 & 48 \\
\hline 12 & 39 & 51 & 53 & 47 \\
\hline 13 & 40 & 49 & 54 & 46 \\
\hline 14 & 38 & 49 & 54 & 46 \\
\hline 15 & 38 & 47 & 53 & 47 \\
\hline 16 & 36 & 48 & 53 & 45 \\
\hline 17 & 35 & 50 & 51 & 44 \\
\hline 18 & 34 & 47 & 51 & 42 \\
\hline 19 & 34 & 46 & 50 & 44 \\
\hline 20 & 35 & 44 & 48 & 43 \\
\hline 21 & 33 & 46 & 48 & 42 \\
\hline 22 & 32 & 45 & 48 & 42 \\
\hline 23 & 30 & 45 & 47 & 43 \\
\hline 24 & 30 & 46 & 47 & 41 \\
\hline 25 & 31 & 44 & 48 & 41 \\
\hline$\Delta \max$ & 12 & 13 & 11 & 13 \\
\hline & & & & \\
\hline
\end{tabular}

\section{E. Discussion}

According to presented research, we can give the answer for stated question: Can VR be useful in medicine, especially can it help to overcome a psychical trauma? The initial research results, as we documented in graphical and table form, show definitely positive indicators that VR can be helpful in therapy of PTSD patients in our case of pensioners.
Certainly, the impact and effect of PTSD VR therapy can be boosted.

Firstly, overall VR experience would be much more realistic with using $360^{\circ}$ videos and photos recorded in authentic Czech environment. For this research, there were used mostly $360^{\circ}$ videos and photos coming from outside the Czech Republic. The best option would be the $360^{\circ}$ video recorded in respondent's ordinary surrounding or in his/her trauma birth place.

Secondly, with using a different and more sophisticated type of VR device, the overall VR experience could be better, richer and deeper. VR device Samsung Gear VR, which was used in the presented research allow only static VR experience. It means, there is no real movement like in a real life and there is no touch response. For example, with HTC Vive which is planned for the next research, there would be more authentic simulation of walking in $3 \mathrm{D}$ virtual surrounding or holding of something.

Although this research was done with a small group of people who were affected by PTSD, it appears that VR can be useful in medical areas. To be sure with the argument that VR has a markedly important role in dealing with PTSD, it is relevant to make bigger research in which a larger sample of respondents is investigated. This kind of extended research is prepared.

Detailed paper about the measurement of the basic physiological body functions from this research is also further planned.

\section{CONCLUSIONS}

The most important question of this paper was to find out if VR can be used as a tool to help and heal pensioners suffering from PTSD. PTSD disrupts their whole life - their relationships, their well-being and their happiness from everyday activities. If people suffer from PTSD, they are more often open and allowable to other mental problems for example depression, eating problems, alcohol, drugs and in the worst scenario also thoughts about suicide.

The results of our tests (BFNE, BAI, TMT and PCL-5) after the application of the 6-months long research intervention at the time intervals are promising because there are provable decreases in depression stress. These results are expressed in quantity $\Delta$ where the biggest value $\Delta \max$ was measured for the respondent 1 with $\triangle \max =15$ in BFNE. In BAI, the biggest value $\Delta$ max was measured for the respondent 4 with $\Delta \max =17$. Situation in TMT tests were 
following, the biggest value $\Delta \max$ in TMT (part A) was $\Delta \max =14$ for the respondent 4 and in TMT (part B) was $\Delta \max =44$ for the respondent 2 . In our last PCL-5 test, the biggest $\Delta \max$ was measured for the respondents 2 and 4 with $\Delta \max =13$ for both. From the gained results can be deducted that we can start talking about the clinically positive change.

The paper shows that VR can be used for visualization of situations where unhealthy people can easily and regularly learn how to work with their anxiety. VR can be used also for other practices. For example, it can be used to relax and have fun.

As can be deduced from other research papers and also from this paper, there are generally positive impacts of VR on human health. [2], [3], [4]

VR has a widely positive impact on a person's mental health. It is certain that this modern technology will continue to be developed and refined, making it even more widely applicable in supporting human's health.

\section{ACKNOWLEDGMENT}

There was a help for this research by grant no. IGA/CebiaTech/2019/003 from Tomas Bata University in Zlin.

\section{REFERENCES}

[1] P. Havlikova, Aktualni a potenciálni farmakologicke moznosti lecby posttraumaticke stresove poruchy. Psychiatrie pro praxi [online]. Psychiatricka nemocnice Sternberk, 2017, 18(2), 56-58. Available: https://www.psychiatriepropraxi.cz/pdfs/psy/2017/02/02.pdf

[2] J. Prasko, B. Paskova, N. Soukupova and V. Tichy, Posttraumaticke stresove poruchy: I. dil klinicky obraz a etiologie. Psychiatrie pro praxi [online]. 2001, (4), 157-160. Available: https://www.psychiatriepropraxi.cz/pdfs/psy/2001/04/04.pdf

[3] A. Azarang, M. Pakyerek, C. Giroux, T. E. Nordahl and P. Yellowlees, Information Technologies: An Augmentation to PostTraumatic Stress Disorder Treatment Among Trauma Survivors. Telemedicine and e-Health [online]. 2019, 25(4), 263-271. ISSN 1530-5627.

https://www.liebertpub.com/doi/10.1089/tmj.2018.0068

[4] B. Sobota and F. Hrozek, Virtualna realita a jej technologie. Ostrava: Datakon Znalosti, 2013. ISBN 978-80-248-3189-3.

[5] H. Tran, M. Nguyen, H. Le and W. Q. Yan, A personalised stereoscopic 3D gallery with virtual reality technology on smartphone. In: 2017 International Conference on Image and Vision Computing New Zealand (IVCNZ). IEEE, 2017, ISBN 978-1-53864276-4. Available: https://ieeexplore.iee.org/document/8402456/

[6] J. M. Carmen, I. Garcia-Garcia, R. Molla and R. Lopez, Users' Perceptions Using Low-End and High-End Mobile-Rendered HMDs: A Comparative Study. Computers [online]. 2018, 7(1). DOI: 10.3390/computers7010015. ISSN 2073-431X. Available: http://www.mdpi.com/2073-431X/7/1/15
[7] V. Highfield, T. Mcmullan and J. Bray, Samsung Gear VR review: What you need to know. Alphr [online]. 2018. Available: https://www.alphr.com/samsung/samsung-gear-vr/1002842/samsunggear-vr-review

[8] A. Hernandez-Martinez, J. Rodriguez-Almagro, M. Molina-Alarcon, N. Infante-Torres, M. D. Manzanares and J. M. Martinez-Galiano, Postpartum post-traumatic stress disorder: Associated perinatal factors and quality of life. Journal of Affective Disorders [online]. 2019, 249, 143-150. DOI: 10.1016/j.jad.2019.01.042. ISSN 01650327. Available: https://linkinghub.elsevier.com/retrieve/pii/S0165032718327964

[9] L. R. Grasser and A. Javanbakht, Treatments of Posttraumatic Stress Disorder in Civilian Populations. Current Psychiatry Reports [online]. 2019, 21(2). ISSN 1523-3812. Available: http://link.springer.com/10.1007/s11920-019-0994-3

[10] Post-traumatic stress disorder (PTSD). Mayo Clinic [online]. 2018. Available: https://www.mayoclinic.org/diseases-conditions/posttraumatic-stress-disorder/symptoms-causes/syc-20355967

[11] R. Parekh, What Is Posttraumatic Stress Disorder? The American Psychiatric Association [online]. 2017. Available: https://www.psychiatry.org/patients-families/ptsd/what-is-ptsd

[12] J. M. Oulton, D. Strange, R. D. V. Nixon and M. K. T. Takarangi, PTSD and the role of spontaneous elaborative "nonmemories". Psychology of Consciousness: Theory, Research, and Practice [online]. 2018, 5(4), 398-413. DOI: 10.1037/cns0000158. ISSN 2326-5531. http://doi.apa.org/getdoi.cfm?doi=10.1037/cns0000158

[13] A. Tavoli, M. Melyani, M. Bakhtiari, G. H. Ghaedi and A. Montazeri, The Brief Fear of Negative Evaluation Scale (BFNE): translation and validation study of the Iranian version. BMC Psychiatry. 2009, 9(1), -. DOI: $10.1186 / 1471-244 X-9-42$. ISSN 1471-244X. Available: http://bmcpsychiatry.biomedcentral.com/articles/10.1186/1471244X-9-42

[14] A. Muntingh, Ch. M. Van Der Feltz-Cornelis, H. V. Marwijk, P. Spinhoven, B. Penninx and A. Van Balkom, Is the beck anxiety inventory a good tool to assess the severity of anxiety? A primary care study in The Netherlands study of depression and anxiety (NESDA). BMC Family Practice. 2011, 12(1), -. DOI: 10.1186/1471-2296-12-66. ISSN 1471-2296. Available: http://bmcfampract.biomedcentral.com/articles/10.1186/1471-2296$12-66$

[15] T. Tombaugh, Trail Making Test A and B: Normative data stratified by age and education. Archives of Clinical Neuropsychology [online]. 2004, 19(2), 203-214. DOI: 10.1016/S0887-6177(03)00039-8. ISSN 08876177. Available: https://academic.oup.com/acn/articlelookup/doi/10.1016/S0887-6177(03)00039-8

[16] E. Heerema and C. Chaves, Administration, Scoring and Interpretation of the Trail Making Test: How Effective Is the Trail Making Test in Identifying Dementia?. VeryWell health [online]. 2018. Available: https://www.verywellhealth.com/dementiascreening-tool-the-trail-making-test-98624

[17] C. Blevins, F. W. Weathers, M. T. Davis, T. K. Witte and J. L. Domino, The Posttraumatic Stress Disorder Checklist for DSM-5 (PCL-5): Development and Initial Psychometric Evaluation. Journal of Traumatic Stress [online]. 2015, 28(6), 489-498. DOI: 10.1002/jts.22059. ISSN $08949867 . \quad$ Available: http://doi.wiley.com/10.1002/jts.22059

[18] F.W. Weathers, T. M. Keane, P. A. Palmieri, B. P. Marx and P. P. Schnurr, The PTSD Checklist for DSM-5 (PCL-5). Scale available from the National Center for PTSD at www.ptsd.va.gov. 